\title{
Understanding and learning from organisational failure
}

\section{$K$ Walshe}

\section{Healthcare systems need better mechanisms for identifying, investigating, and learning from major organisational failures if they are to prevent such failures occurring in the future.}

$\mathrm{E}$ very healthcare system has its disasters-high profile failures of care in which many patients are harmed, perhaps seriously, and lives are often lost. In the UK such tragic circumstances have come to light with alarming regularity in recent years, ${ }^{1}$ and there has been a series of public inquiries into, for example, avoidable deaths in paediatric cardiac surgery in Bristol, negligent clinical practice in gynaecology in Kent, inappropriate post-mortem tissue removal and retention from children in Liverpool and, most recently and horrifically, the murder of over 200 patients in a period of 23 years by a general practitioner in Manchester. ${ }^{2}$ The cumulative effect of this litany of misadventure is hard to judge, but it has certainly contributed to reducing the willingness of the public and the media to place their trust in clinical professionals and healthcare organisations, and has fuelled calls for more regulation and oversight of clinical practice and the performance of healthcare organisations.

Although the anatomy of these disasters is largely clinical-botched surgery, negligent diagnosis or treatment, errors in prescribing or administering drugs, clinical incompetence, and so onsubsequent inquiries and investigations suggest that their pathology is almost always organisational. ${ }^{3}$ These problems seem to happen in organisations with inadequate or weak leadership; organisational or geographical isolation and an inward looking closed culture; a lack of basic management systems and processes such as performance review and management; poor internal and external communication and a lack of openness or transparency; and disempowered groups of staff and patients who are unable to voice their concerns. ${ }^{4}$ Armed with this knowledge, one might expect that we could identify those organisations (or parts of them) which are prone to failure and prevent future failures from occurring. But the dismal repetitiveness with which such organisational failures happen suggests that this is far from straightforward. For example, in social care we have seen a succession of inquiries into the deaths of children at the hands of their parents or carers over the last 30 years, ${ }^{5}$ culminating most recently in the case of Victoria Climbie discussed in the accompanying editorial by Marcovitch. ${ }^{6}$ After each inquiry, social workers, healthcare professionals, educators, the police, and other public services have been castigated for failing to spot the obvious signs that children were at risk and failing to act to protect them in time. In each case a picture has emerged of organisational failure-poor communication, inadequate systems for record keeping and case management, unrealistic workloads, weak or absent middle and senior management, and a lethargic culture of learned helplessness in which unacceptably poor standards of care become the norm. Each inquiry or investigation makes many recommendations but they are either not implemented or they do not work, for the tragedies keep happening.

There may be three reasons for this, related to (1) the way that instances of organisational failure are identified; (2) our approach to investigating and understanding their causes; and (3) the mechanisms for using that understanding to bring about changes which would make future recurrence less likely. ${ }^{7}$

Firstly, it is almost wholly a matter of chance whether an instance of organisational failure is brought to the surface and exposed, or lies concealed. Healthcare organisations and the healthcare professions have traditionally dealt with such problems informally and secretively, and it seems likely that there are many more instances of such disasters which never attract widespread public and media attention and are never subject to a formal inquiry or investigation. In some countries the process of medical negligence litigation reinforces this tendency to concealment through the use of non-disclosure agreements and out of court settlements, and market pressures among competing healthcare providers mean there are strong disincentives to honesty and openness. The responsibility for identifying major organisational failures and initiating an investigation is often fragmented between professional regulators, healthcare providers, and government authorities. A better and clearer definition of the circumstances or instances which should trigger a formal investigation of organisational failure is needed, alongside more robust and coherent systems for initiating and managing such investigations or inquiries.

Secondly, the techniques used for understanding and learning from the causes of organisational decline and failure in healthcare organisations are rather limited. In the UK we rely too much on the reports of individual, ad hoc inquiries and investigations which are effectively single case studies of instances of organisational failure. These are often conducted by an inquiry panel led by a lawyer, which takes a quasijudicial approach to finding out what happened and may be more effective at describing the events with forensic accuracy than at prescribing effective organisational changes which would prevent them happening again. The process of investigation is often slow and costly, but still lacks rigour and sophistication. Moreover, we have no mechanisms for accumulating investigatory expertise and building up a cumulative understanding of organisational failure across a series of such events.

Thirdly, there are few-if anymechanisms for following up inquiries and investigations and ensuring that other healthcare organisations have learned from past mistakes and made changes which would make their recurrence less likely. Once an inquiry report has been published, public and media attention is short lived and the boring but crucial process of implementing its recommendations and making changes happen is often not followed through, or is left up to healthcare providers and professionals to do with little support or oversight. Unsurprisingly, some are better than others at this, and it seems reasonable to hypothesise that those organisations which are least effective at making such changes happen may also display more of the common characteristics or determinants of organisational failure which were outlined earlier.

If healthcare systems had better mechanisms for identifying, investigating, and learning from major organisational failures, they would almost certainly be better at preventing such failures in the future, and so would avoid the considerable harm that often results for patients, clinical professionals, and healthcare organisations. At the same time, more research is needed to develop a better, theoretically informed, and empirically grounded understanding of the causes and determinants of organisational failure and how they can be prevented. 
This editorial draws upon current research into major organisational failures in health care which is supported by the Commonwealth Fund, a New York City-based private independent foundation. The views presented here are those of the author and not necessarily those of the Commonwealth Fund, its director, officers or staff.

Qual Saf Health Care 2003;12:81-82

Author's affiliation

K Walshe, Director of Research and Reader in Public Management, Manchester Centre for

Healthcare Management, University of
Manchester, Devonshire House, University Precinct Centre, Oxford Road, Manchester M13 9PL, UK; kieran.walshe@man.ac.uk

\section{REFERENCES}

1 Walshe K, Higgins J. The use and impact of inquiries in the NHS. BM 2002;325:895900.

2 Smith J. The Shipman inquiry: first report. London: HMSO, 2002

3 Walshe K, Offen N. A very public failure: lessons for quality improvement in healthcare organisations from the Bristol Royal Infirmary. Qual Health Care 2001; 10:250-6.

4 Higgins J. The listening blank. Health Serv J $2001 ; 111: 22-5$.

\section{Learning from tragedies: clinical lessons from the Climbié report}

\section{H Marcovitch}

\section{Improvements in communications between healthcare workers and changes in consultant work plans are needed if we are to avoid another tragedy like that of Victoria Climbié.}

n January 2001 in London, 8 year old Victoria Climbié's great-aunt and her partner were convicted of her murder. During the last few months of her life she had come to the attention of doctors in two hospitals and social workers in two local authorities, but she remained unprotected. In consequence, the Secretary of State for Health set up an independent inquiry under a senior judge, Lord Laming. It reported in January 2003.

Unusually, given the history of enquiries into similar cases in the UK, the prime criticism was directed not to those Lord Laming referred to as " . . . the handful of hapless, if sometimes inexperienced, front line staff", but to " . . the managers and senior members of the authorities whose task it was to ensure . . . services for children like Victoria ...".

The report calls for major national organisational changes: the Government has promised to respond this spring. It seeks further training for paediatricians and general practitioners which will be delegated to their Royal Colleges. Social service departments are given a list of tasks, as are National Health Service trusts. I shall deal only with the last of these.

NHS chief executives will have to complete an audit by the end of April on how they protect children. In May the Secretary of State will have the results, collated by the Commission for Health Improvement, on his desk.
In keeping with the thrust of Laming's critique, it will be "managers and senior members" rather than clinicians who will be responsible for undertaking this task. Nonetheless, there is a paradox as 10 of the 16 priority recommendations directed at healthcare workers direct doctors how they should behave when dealing with individual patients. Of the other six, one involves provision of interpreters where needed, one the correct completion of the identification sheet for every new patient contact, and just four require chief executives to carry out a governance role in monitoring the compliance of clinicians with certain aspects of their work with abused children. The moral and ethical responsibility will stay where it should be-with clinicians who owe children a duty of care. The onus therefore remains on front line staff, even though Laming appears to suggest otherwise.

The report's findings with regard to the hospital departments which dealt with Victoria make clear why this should be. Ten doctors in two paediatric units dealt with Victoria during her admissions of just over 24 hours and 14 days, respectively. Only one is accused by Laming of failing to diagnose physical abuse. Issues raised included:

- A nursing care plan did not refer to abuse even though it had been diagnosed by the admitting doctor.

- Doctors should interview such children alone (or with an interpreter)
5 Noyes P. Child abuse: a study of inquiry reports 1980-1989. London: Department of Health, 1991.

6 Marcovitch $\mathbf{H}$. Learning from tragedies: clinical lessons from the Climbié report. Qual Saf Health Care 2003;12:82-3

7 Walshe K. Inquiries: learning from failure in the NHS. London: Nuffield Trust, 2003.

8 Rosenthal M. The incompetent doctor: behind closed doors. Buckingham: Open University Press, 1995.

without fear of compromising social service investigations.

- If a registrar and consultant disagree on diagnosis, their discussion should be noted.

- Delegated note keeping should be checked and agreed.

- Telephone or face-to-face discussions about a child must be recorded.

- Senior house officers (SHOs, junior residents) or nurses may not discharge such children from hospital and there must be a documented follow up plan.

- A full physical examination must be performed and documented within 24 hours of admission.

- Difficult conversations with possible abusers should not be left to SHOs.

- Doctors must provide full reports to social services departments and correct misunderstandings in writing.

Paediatricians reading this list may be forgiven for assuming they represent a summary of normal practice and asking themselves why it did not happen in this case. Few of the reasons have to do with inadequate medical knowledge. Most have to do with poor note keeping skills or chaotic working patterns.

At one point a specialist registrar who made a correct and prompt diagnosis had gone off duty by the time the consultant arrived because the latter was conducting a community clinic. They never conferred.

A registrar wrote a note of a consultant's ward round. The two doctors subsequently disputed the accuracy of the note. One question was whether "no physical abuse issues" would have been preferable to "no child protection concerns".

A locum SHO wrote a referral slip to the duty social worker. She believed it would provoke a visit. Laming pointed out the letter did not ask for a visit. It began: "Thank you for dealing with the social issues [of this child]".

Three separate messages were sent to a social worker but none referred unequivocally to non-accidental injury. The 
social worker wrote to the ward sister requesting confirmation but this memo never reached the eyes of a doctor, presumably being filed within nursing notes.

An SHO noted: “ . . . For home visit today with police. ?Discharge after that if it is safe". He informed the enquiry that his note implied: "if we had received a report from police and social services that they had a safe place for her to go she may possibly be discharged". The nurse who sent her home a few hours later assumed the note implied a definite discharge plan and further assumed (wrongly) that the police had conducted their visit.

$$
\begin{aligned}
& \text { "doctors [should be taught] how to } \\
& \text { write [so] that readers will } \\
& \text { understand" }
\end{aligned}
$$

This brief resumé of a complex tale leads me to suggest some potential solutions. Any colleague who has examined case notes in the course of investigating a complaint or providing an expert report to a court will know the frustration of not being able to conjure up a picture of what happened from the written account. It is not a question of lengthrather of accuracy - as is apparent from the extracts above. Conflation of factual findings with speculation is commonplace. The use of shorthand ("?discharge") may not mean what was intended to those schooled using a different jargon. I suggest it is time to resurrect problem orientated medical records $\mathrm{s}^{23}$ which separate objective findings from subjective interpretation, prefer an assessment (by necessity discursive) not a diagnosis (proscriptive), and demand a plan every time a note is made. Furthermore, each problem identified should be numbered and listed on each subsequent occasion. In the meantime, when writing notes, SHOs might like to recall the "pub" test ("If I read this out to someone in the pub would they know what I was talking about?"4). For those who prefer something fancier, how about "narrative"? Laming rightly asks for paediatricians to be further trained. I think we should start at medical school by teaching doctors how to write in such a way that readers will understand.

As to the horrors of rotas and shifts, it may be impracticable to demand face-toface meetings but, in their place, there has to be a thorough handover note. This must be read and, if disputed, the differences of opinion detailed for all to see, then argued out in person at the next available opportunity. In any case it is surely not acceptable to be responsible for acute admissions, even if delegated to trainees, at the same time as conducting a non-acute clinic outside the hospital. Acute paediatric medicine involves being immediately available for consultation and coexists uncomfortably with the multitude of other tasks expected of NHS consultants. Chief executives should make sure that consultant work plans clearly separate acute and nonacute work.

History forbids pious hopes that there will be no other Victorias in years to come. But we can try.

Qual Saf Health Care 2003;12:82-83

\section{Author's affiliation}

H Marcovitch, Editor, Archives of Disease in Childhood, BM Journals, BMA House, London WC1H 9JR

Correspondence to: Harvey Marcovitch Honeysuckle House, Balscote, Oxford OX15 6JW, UK; h.marcovitch@btinternet.com

\section{REFERENCES}

1 The Victoria Climbié Inquiry. Cm 5730. London: The Stationery Office, 2003

2 Weed LL. Medical records that guide and teach, 1. N Engl J Med 1968;278:503-600.

3 Weed LL. Medical records that guide and teach, 2. N Engl J Med 1968:278:652-7.

4 Albert T. A-Z of medical writing. London: BMU Books, 2000.

Another ehealth applicationThe future for primary care: increased choice for patients

\section{R Evans, A Edwards, G Elwyn}

\section{Goodbye primary care-please hold and you will be connected to a new definition ... .}

$\mathrm{P}$ rimary care is changing. No longer is it confined exclusively to the GP surgery or health centre, and nor are the routine contacts restricted to "office hours". There have been many recent consumer driven changes to the delivery of health care in the UK. "Walk in" centres-NHS and private-provide a service to consumers who find themselves unable to access GP surgeries. ${ }^{1}$ Many people, for instance, may commute long distances to work and find their GP opening hours are too restrictive. On the other end of the social spectrum, homeless patients often prefer to access "drop in centres" ${ }^{\prime 2}$ where the services are better orientated to their needs. Another development is the UK telephone and online service, NHS Direct, which offers patients both information and advice-for many it is now their first contact with the health service.

But the most dramatic change to primary care lies in consumer health informatics, or ehealth. ${ }^{4}$ Consumers can now access an unparalleled wealth of health information via the internet. The National electronic Library for Health (www.nelh.nhs.uk) is a UK resource available to both staff and patients which provides links to a host of other related sites. Some such as NHS Direct online (www.nhsdirect.nhs.uk) use the interactivity of the internet to allow consumers to receive information and advice tailored to their own specific health needs. ${ }^{5}$ interactive decision explorers (iDEXs)assists patients in making decisions on difficult issues such as benign prostatic hyperplasia treatments ${ }^{6}$ or hormone replacement therapy. ${ }^{7}$ Exciting opportunities are offered by multimedia and broadband technology: consumers will increasingly be able to access digital audiovisual information rapidly. DIPEx (www.dipex.org), for instance, is a website that already uses this to great effect-patients present their own personal experiences of cancer. ${ }^{8}$

The opportunities for consumers will advance further with the development of the "single electronic health record" which is being developed by a number of countries and organisations for their patients. ${ }^{9}$ The obvious benefits for a large complex organisation such as the UK NHS are consistency and availability of information throughout the system. But who will own this information? It is likely that consumers will demand ownership—and why not? After all, they already control their financial and other personal details. Armed with their single electronic health record, consumers will be able to exercise an unprecedented degree of choice. Moving between GP surgeries and "walk in" centres will become far easier and conversations 
with telephone health services will become much more meaningful. Consumers will also be able to use their electronic record to engage far more productively with interactive ehealth applications; these, in turn, will become much more sophisticated.

$$
\begin{aligned}
& \text { "...primary care must be } \\
& \text { defined from the consumer's } \\
& \text { perspective..." }
\end{aligned}
$$

In this changing field, the quality and safety debate must also develop and adapt quickly. Maxwell's criteria, for instance, contained six elements: effectiveness, efficiency, equity, access, acceptability and appropriateness..$^{10}$ All are relevant to the newer elements of primary care. The issue of social equity in accessing health informatics - the "digital divide" - has come to the forefront of public debate. Nonetheless, reflecting the need for change, others have expanded on these criteria: Moss, for instance, suggested that respect, choice, and availability of information should be included. ${ }^{1}$ In the case of health informatics, and particularly healthcare websites, there has been a proliferation of quality measures; 51 were recently identified-none had been validated. ${ }^{12}$ In a sense this merely reflects the diversity and dynamism of ehealth. On the other hand, the potential for misinformation and patient harm is clearly a serious concern; the European Union recently defined a set of quality criteria for health related websites in terms of transparency and honesty, authority, privacy and data protection, updating of information, accountability, and accessibility. ${ }^{13}$
Before developing and applying these quality criteria, however, we must first be clear about what is now understood by the term "primary care". The definitions of primary care we have at present are outdated. They are usually service led $^{14}$ and frequently draw on the differences and tensions between primary and secondary care..$^{15}$ In these cherished definitions, primary care is centred on the all encompassing local GP centre ${ }^{16}$ where care is delivered in the context of a reformist public health and political agenda. ${ }^{17}$ Clearly, it is time to move on. However painful to the medical perspective, primary care must be defined from the consumer's perspective-a consumer who will increasingly seek health advice from an ever diversifying range of sources.

But, crucially, the consumer will also demand quality and safety from this newly conceptualised "primary care". The quality criteria can be specified once a new definition of primary care has been agreed. We therefore propose a new definition of primary care: "A consumer's initial health care interactionhuman or electronic".

Qual Saf Health Care 2003;12:83-84

\section{Authors' affiliations}

R Evans, A Edwards, G Elwyn, Department of Primary Care, University of Wales Swansea Clinical School, Swansea SA2 8PP, UK

Correspondence to: Dr R Evans, Department of Primary Care, University of Wales Swansea Clinical Schoolk, Swansea SA2 8PP, UK ; rhodri.evans@btinternet.com

\section{REFERENCES}

1 Salisbury C, Chalder M, Scott TM, et al. NHS? BMJ 2002 walk-in centres in

2 Morrison CL, Ruben SM. The development of healthcare services for drug misusers and prostitutes. Postgrad Med J 1995;71:593-7. 3 George S. NHS Direct audited BM 2002;324:558-9.

4 Eysenbach G. Recent advances: consumer health informatics. BMV 2000:320:1713-6.

5 Eaton L. NHS Direct Online explores partnerships with other health organisations. BM 2002;324:568.

6 Murray E, Davis H, Tai SS, et al. Randomised controlled trial of an interactive multimedia decision aid on benign prostatic hypertrophy in primary care. BM 2001;323:493-6.

7 Murray E, Davis H, Tai SS, et al. Randomised controlled trial of an interactive multimedia decision aid on hormone replacement therapy in primary care. BM 2001;323:490-3.

8 Chapple A, Ziebland S, Shepperd S, et al. Why men with prostate cancer want wider access to prostate specific antigen testing: qualitative study. BN 2002;325:737.

9 Welsh Assembly Government. Informing healthcare. Cardiff: Health Information Management Technology and Estates Division, Welsh Assembly Government, 2002.

10 Maxwell RJ. Dimensions of quality revisited: from thought to action. Qual Health Care 1992:1:171-7.

11 Moss F. Quality in health care: getting to the heart of the matter. In: The quest for excellence: essays in honour of Robert $J$. Maxwell. London: King's Fund, 1998.

12 Gagliardi A, Jadad AR. Examination of instruments used to rate quality of health information on the internet: chronicle of a
voyage with an unclear destination. BM voyage with an uncle
$2002 ; 324: 569-73$.

13 Commission of the European Communities eEurope. Quality criteria for health-related websites. J Med Internet Res 2002;4:e15

14 Donaldson M, Yordy K, Vanselow N. Defining primary care: an interim report. Washington DC: Institute of Medicine, 1994

15 Heath I. The mystery of general practice. London: Nuffield Provincial Hospitals Trust, 1995.

16 Gordon P, Plamping D. Primary health care: its characteristics and potential. In: Hadley J,
ed. Extending primary care. Oxford: Radcliffe ed. Extending primary care.

17 Starfield B. Is primary care essential? Lancet 1994;344:1 129-33. 